\title{
A review and outlook in the treatment of osteosarcoma and other deep tumors with photodynamic therapy: from basic to deep
}

\author{
Wei Yu ${ }^{1,2}$, Jian Zhu ${ }^{1,2}$, Yitian Wang ${ }^{1,2}$, Junjie Wang ${ }^{1,2}$, Weijing Fang $^{1,2}$, Kaishun \\ $\mathrm{Xia}^{1,2}$, Jianlin Shao ${ }^{3}$, Minzu Wu ${ }^{4}$, Bing Liu ${ }^{1,2}$, Chengzhen Liang ${ }^{1,2}$, Chengyi $\mathrm{Ye}^{1,2}$ and \\ Huimin Tao ${ }^{1,2}$ \\ ${ }^{1}$ Department of Orthopedics, 2nd Affiliated Hospital, School of Medicine, Zhejiang University, Hangzhou, Zhejiang, PR China \\ ${ }^{2}$ Orthopedics Research Institute of Zhejiang University, Hangzhou, Zhejiang, PR China \\ ${ }^{3}$ La Jolla Institute for Allergy and Immunology, La Jolla, CA, USA \\ ${ }^{4}$ Salk Institute for Biological Studies, La Jolla, CA, USA \\ Correspondence to: Huimin Tao, email: huimintao_zrgk@163.com
}

Keywords: osteosarcoma; photodynamic; target therapy; nanotechnology; immunotherapy

Received: November 16, 2016 Accepted: February 07, $2017 \quad$ Published: March 15, 2017

Copyright: Yu et al. This is an open-access article distributed under the terms of the Creative Commons Attribution License (CC-BY), which permits unrestricted use, distribution, and reproduction in any medium, provided the original author and source are credited.

\section{ABSTRACT}

Photodynamic therapy, one of the most promising minimally invasive treatments, has received increasing focus in tumor therapy research, which has been widely applied in treating superficial tumors. Three basic factors - photosensitizer, the light source, and oxidative stress - are responsible for tumor cell cytotoxicity. However, due to insufficient luminous flux and peripheral tissue damage, the utilization of photodynamic therapy is facing a huge limitation in deep tumor therapy. Osteosarcoma is the typical deep tumor, which is the most commonly occurring malignancy in children and adolescents. Despite developments in surgery, high risks of the amputation still threatens the health of osteosarcoma patients. In this review, we summarize recent developments in the field of photodynamic therapy and specifically PDT research in OS treatment modalities. In addition, we also provide some novel suggestions, which could potentially be a breakthrough in PDT-induced OS therapies. PDT has the potential to become an effective therapy while the its limitations still present when applied on the treatment of OS or other types of deep tumors. Thus, more researches and studies in the field are required.

\section{INTRODUCTION}

Osteosarcoma (OS) is a common primary bone sarcoma in humans, ordinarily manifesting as osteogenesis by malignant cells [1]. Today, with improved techniques, the overall survival rate has increased to $70-80 \%[2,3]$. However, this represents only partial success because of the continuing high rates of limb amputation and pulmonary metastasis [3,4]. Despite being the most important, surgery can result in large bone defects in the affected limb and complex skeletal rebuilding, limiting its application [5]. Chemotherapy is also a common treatment method for OS. But the shortage of satisfactory drugs and multiple side effects still bothers both clinicians and patients [6]. Although the patient life quality has been improved because of the neoadjuvant chemotherapy, the toxicity, lung metastases, and in situ recurrence still threaten OS patients $[7,8]$. Thus, the effective OS therapies are still required.

\section{PHOTODYNAMIC THERAPY}

Photodynamic therapy (PDT) is a novel treatment in cancer research, which has the potential to be part of the next generation of cancer therapy. The antineoplastic effects of PDT depend on three pivotal aspects - photosensitizers, light sources, and oxygen [9]. 


\section{PHOTOSENSITIZERS}

The photosensitizer (PS) requires two important features: 1) it is non-toxic to normal tissue in the dark, and 2) it cause photodamage with an appropriate light source without temperatures rise, distinguishing PDT from photothermal therapy $[10,11]$. These features determine the target cytotoxicity with irradiation. Each PS has an exciting light with optimum wavelength. When exposed to this light, the electrons of the PS transition from a ground singlet state to a higher-energy-level orbit and the PS is then in an excited state. The higher-energy-level electron tends to return to its basal level spontaneously, transmitting energy to a molecule nearby $[9,12,13]$. Thus, light energy is transformed to chemical energy, induced via the PS (Figure 1).

The typical PSs were mostly based on the tetrapyrrole structure such as hiporfin $[9,13]$. Sun's research showed that hiporfin-PDT had an anti-tumor effect to the OS cells, inducing apoptosis and cell cycle arrest at G2/M in vitro [14]. The second generation of PSs includes meso-tetrahydroxyphenyl chlorine (mTHPC), $\delta$-aminolevulinic acid (ALA), and the phthalocyanines. mTHPC is a protoporphyrin that leads to the activation of caspase-dependent apoptosis in the OS therapy when irradiated with 652-nm laser [15, 16]. ALA does not have a tetrapyrrole structure. However, ALA can induce the accumulation of protoporphyrin IX (PpIX) because it promotes heme synthesis, leading to PpIX accumulation under conditions of $\mathrm{Fe}^{2+}$ shortage [17]. White reported that ALA causes cytotoxicity with the human OS cell line, MG-63, and inhibits cell viability in vitro [18].

Although many improvements have been made in the new-generation PSs, many deficiencies remain in deep tumor model. One is their poor solubility [19]. The phthalocyanines (Pcs) are a family of PSs, which have a light absorption peak at $680 \mathrm{~nm}$ [20]. However, hydrophobicity causes the angiemphraxis and organ deposit of Pcs, which dramatically limits the application of Pcs in vitro and vivo. To overcome this, hydrophilic modifications of Pcs have been undertaken, such as sulfonation, and nanocrystallization [19, 21].

The distribution of PSs in the body is also a problem in PDT. Despite nanotechnology and other targeting techniques, PSs still tend to concentrate in the liver, kidney and other tissues in vivo [22, 23]. The nonspecific concentrate of PSs lead to irradiated injury of normal tissues as well as liver and kidney damage. Since the existing PSs are not satisfactory for further PDT development, there is a need for another generation of PSs.

\section{LIGHT SOURCES}

Light sources act as a trigger of PDT, which determines the targeted destruction of tumor tissues in PDT. The light sources are characterized by two factors: wavelength and illumination intensity [24]. The wavelengths of typical PSs are concentrated at 600-800

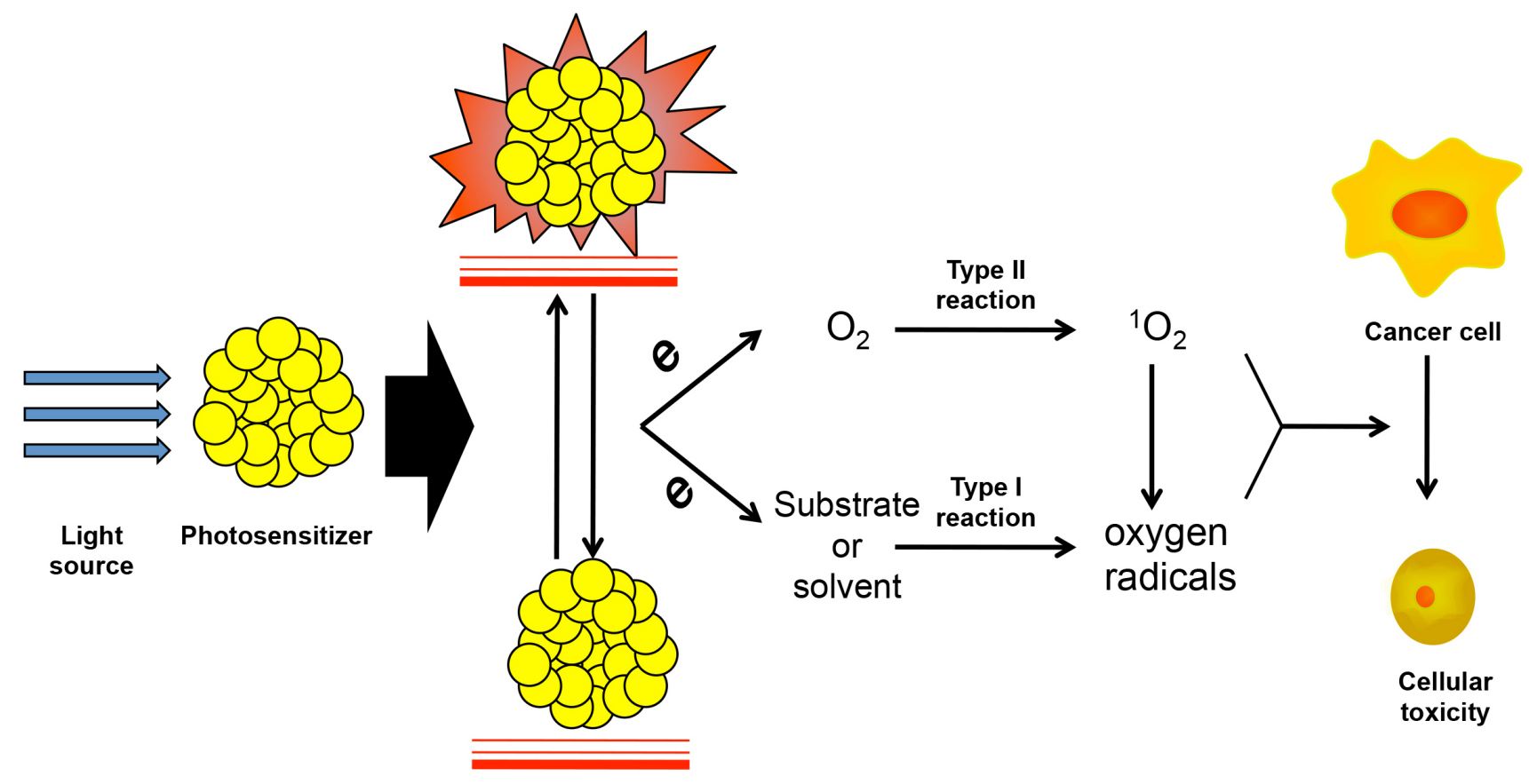

Figure 1: The light-induced PSs activating and ROS producing in PDT. Photodynamic is activated with the irradiation of specific light source, which was transit to high energy level and release the electron when the PSs return to the ground state. The electrons lead to the two types of oxidation reactions. Type I is substrate or solvent induced oxygen radical generation, which is also called reactive oxygen specie (ROS). Type II is the activation of singlet oxygen $\left({ }^{1} \mathrm{O}_{2}\right)$ by oxygen molecule and which also promote the producing of ROS. Both ROS and ${ }^{1} \mathrm{O}_{2}$ contribute to the apoptosis of cancer cells. 
$\mathrm{nm}$ [25], called the near-infrared spectral region (NISR). Given absorption by melanin and obstruction by tissues, the penetrating depth of light is proportional to the wavelength of light within the NISR, whereas ultraviolet (UV) light will be blocked by melanophores and may cause damage to the skin [24]. However, the effective intensity is still too weak for deep tissues within the NISR (Figure 2). And simply enhancing the power of the illuminant will cause the increase of damage in superficial tissues, especially the skin. Thus, it is a challenge to find a novel and appropriate irradiation way in PDT.

First generation light sources are arc lamps, which are convenient and cheap. But the wide light spectrum and the obvious thermal effect block the therapeutic application [26]. As an innovation in lighting technology, lightemitting diodes have become common in PDT because of less injury to superficial tissues, which commonly used in OS researches [27, 28]. However, the light intensity still suffers decay for deep tumor. Consequently, as the little progress of light source has made, there are still many opportunities for innovations regarding PDT light sources in the field of OS.

\section{OXIDATIVE STRESS}

The Oxidative stress activated by light source in PDT can be separated into two major reaction types. Type I reactions primarily involve in substrates or solvents. They generate free radicals, including peroxide anion and superoxide anion radicals, which tend to result in powerful oxidative effects and cause cytotoxicity. They are also part of the group of reactive oxygen species (ROS). Type II reactions contribute to the activation of the oxygen molecule directly. Then, singlet oxygen, the core of the reaction, is produced from the transfer of electrons to $\mathrm{O}_{2}$, which causes cell injury in the tumor (Figure 1) [29, 30]. At the meantime, ${ }^{1} \mathrm{O}_{2}$ will react with substrates or solvents and enhancing Type I reactions induced by ROS. The oxidation induced by PDT can also be blocked by antioxidants, such as vitamin $\mathrm{C}$ and superoxide dismutase, illustrating the protective effects of anti-oxidants in normal tissues [31, 32]. In addition, Cheng used perfluorohexane (PFH), which has high oxygen capacity, as a fortifier for PDT [33]. This indicated depletion of the oxidative effect induced by PS activation.

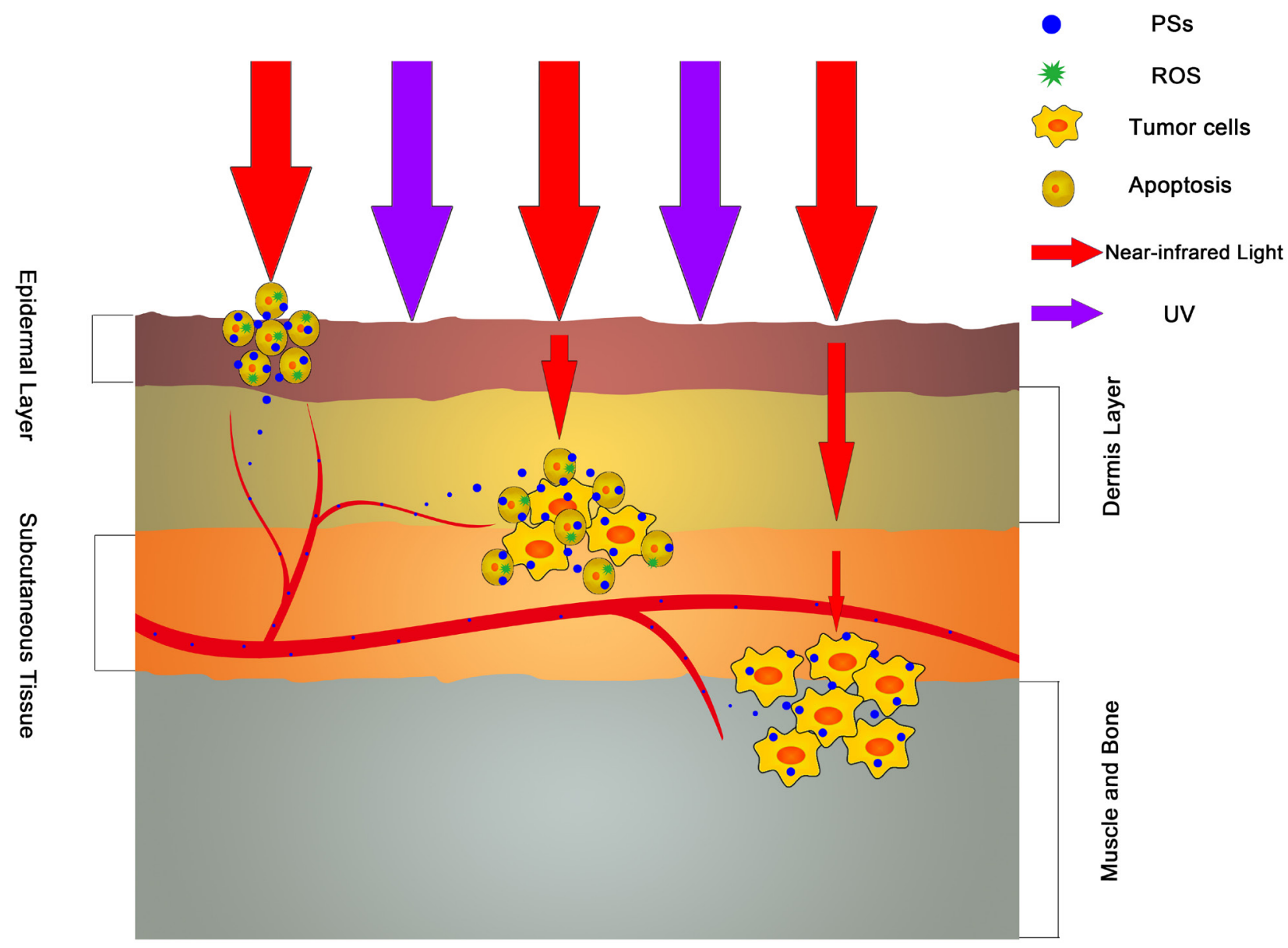

Figure 2: The antitumor effect of various wavelength light sources. The light in NISR can get through the skin and have the cytotoxicity to the tumor cells while UV light will be block in epidermis layer. However, the attenuation of NISR light in different layers of skin and soft tissues will weaken the antitumor effect and cause the Invalidation of PDT. This is the largest barrier of PDT in deep tumor therapy. 
The studies of PDT on OS treatment also focus on the ROS-induce cell death. In Li's research, DCFH-DA was employed to detect the level of ROS in MG-63, which caused the endoplasmic reticulum stress in mitochondrial pathway [34]. This is consistent with other conclusion of PDT on OS treatment [14, 35, 36]. However, because of the high level of metabolism, the oxygen pressure in OS tissue is lower that that in benign tumor and normal tissues, which remarkably limits the anti-tumor effect in OS PDT[37].

\section{APPLICATION OF PDT IN OS AND OTHER DEEP CANCER MODELS}

PDT havs been reported to present the advantage of suppressing multidrug-resistant (MDR) tumors in various deep tumor models [38-40]. The anti-tumor effect induced by PDT in MDR cancers may result from the following: 1) inhibiting some anti-apoptotic proteins, such as those in the Bcl-2 family [41], 2) preventing a drug-efflux effect, damage to ATP-binding transporters [42], 3) altering the microenvironment of tumor cells, including by microvascular injury and inflammatory factor secretion $[43,44], 4)$ enhancing the permeability of tumor vessels and promoting drug delivery [43, 45], and 5) promoting immune system response [46]. The cytotoxicity of PDT to MDR tumor cells, which is the dominate limitation of prognosis improvement to OS patients, is of importance in OS therapy. The study in mouse MDR OS cell line, which is selected by various concentrations of doxorubicin, has indicated that PDT has show no cross resistance to the P-glycoprotein-associated MDR OS cells [47]. These suggest the potential of combining PDT and chemotherapies in OS.
Some studies reported that PSs can serve as a contrast medium in OS treatment, as well as a PDTinduced cytotoxic drug, in magnetic resonance imaging (MRI) with light sources stimulation of different wavelengths. Zeng used $\mathrm{Fe}_{3} \mathrm{O}_{4}-\mathrm{TiO}_{2}$ nanocomposites as effective PSs, and showed darker contrast in T2-weighted MR images [48]. This facilitates the evaluation of tumor inhibition after the PDT-induced treatment and avoids the multiple drug intakes during the oncotherapy and image examination.

Although PDT has been studied on many malignancies for a long time, most researches have focused on superficial cancers, such as skin cancer [49], gastrointestinal cancers [50], head and neck cancers [51], and malignant melanomas [52]. Their location distinguishes these cancers from the tumors in deep tissue, such as glioma, pancreatic cancer, and OS, which suffer from the light deficiencies and surface tissue damage in PDT because of the coverage of muscles and skin.

Given the problem of surface coverage, most of PDT researches were performed in vitro or using subcutaneous tumor models for studying deep tumors. One of substitution models was involved in using a certain thickness of pork tissue as the skin and muscles, covering a subcutaneous tumor $[22,53,54]$. This imitates light decay well and has been used to test the barrier effect of superficial tissues in PDT. However, this model does not overcome the problem of surface injury because of the absence of PSs in the pork outside the body. Thus, this model still needs improving.

Fortunately, the primary pathogenic locations of OS are the proximal tibia and terminal femur, which are more superficial than some other deep tumors. This difference leads to less damage to the skin and muscle. Another application of PDT is on single pulmonary metastasis

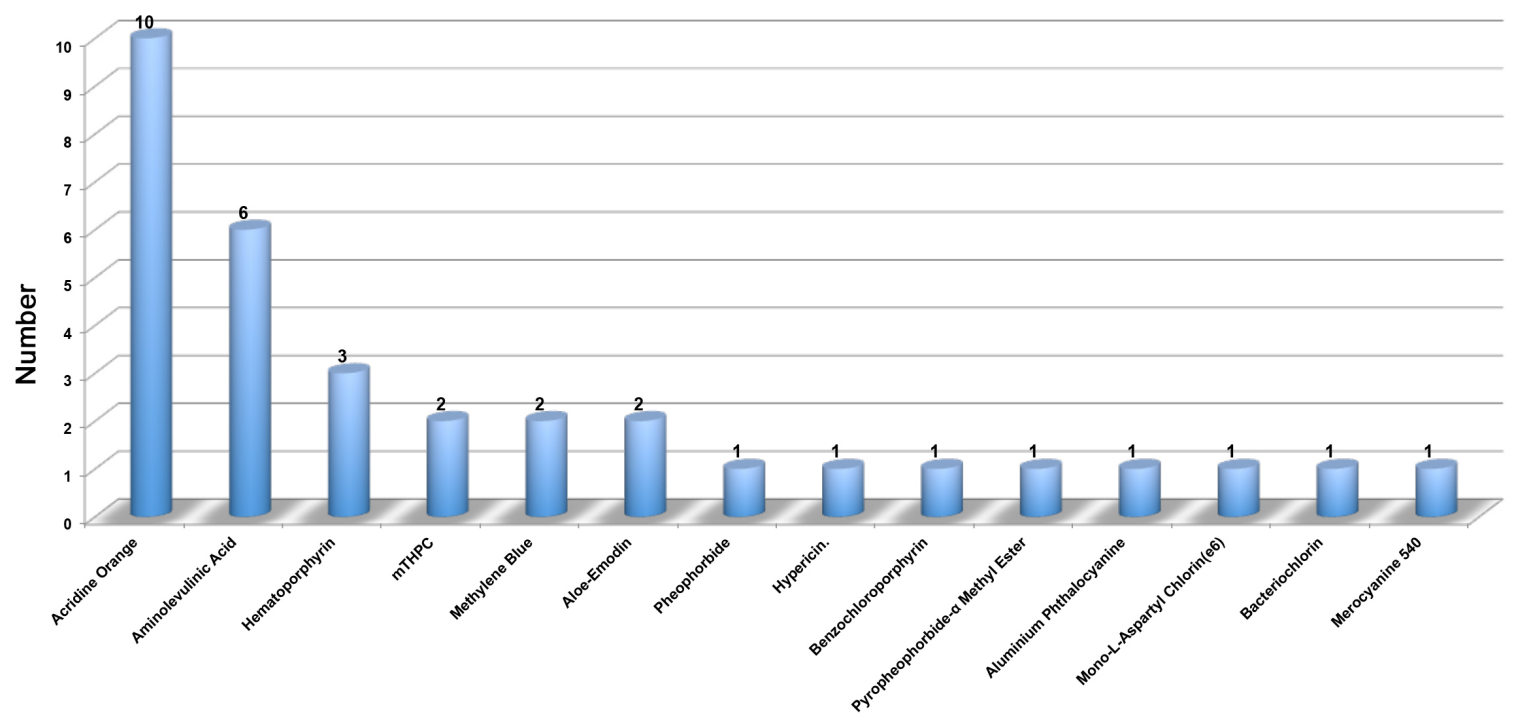

Figure 3: The summarization of various PSs in different PDT researches of OS. This figure summarizes the total PSs of PDT in OS. There are only 31 articles and 14 types of PSs involved in the PDT in OS. 
in OS patients, which is available for irradiation using endoscopy or puncture. Today, researches on PDT in OS are largely stagnant in terms of preclinical studies. Common PSs are limited to acridine orange $[55,56]$, 5-ALA [57, 58], mTHPC [15], hiporfin [14], hypericin [59], and methylene blue [60] in most of OS researches. Studies of PDT in OS are summarized in Figure 3, indicating a shortage of PDT researches in OS.

\section{CYTOTOXIC MECHANISMS OF PDT IN OS}

\section{Autophagy, apoptosis, and necrosis}

Previous studies have shown that autophagy is a major consequence of elevated ROS. It has been reported that ROS can activate autophagy in various ways: 1) $\mathrm{H}_{2} \mathrm{O}_{2}$ can inactivate ATG4 in autophagosome formation and lipidation of ATG8 to promote autophagy. 2) ROS increases AMPK, leading to ULK1-dependent autophagy. 3 ) ROS interrupt the interplay between Beclin and Bcl2 , promoting the initiation of autophagy. 4) ROS can injure mitochondria directly, activating mitophagy. 5) ROS can also strongly activate the phosphorylation of JNK, inducing JNK-dependent autophagy [61, 62]. One of the most recent studies has shown that ROS produced after irradiation can promote the transformation of LC3 II, which activates the phosphorylation of JNK, leading to JNK-dependent autophagy in OS cell lines, MG63 cells. Meanwhile, the further study reveals that the JNK inhibitor blocked the activation of autophagy and increased the cell viability of MG-63 in PDT, which indicated the protective effect of autophagy [35]. These demonstrate the significance of the ROS-JNK induced autophagy pathway in OS PDT.

Besides, apoptosis is another essential pathway in the PDT-induced cell death. ROS decreases the PI3K/AKT signaling pathway, induced by mitochondrial damage, leading to mitochondrion-mediated apoptosis [63]. Recently, it has been shown that there is a balance between apoptosis and autophagy in PDT. In this balance, mTOR alters the PDT-induced cell death between apoptosis and autophagy, involving in mediation by AKT and AMPK [64]. Most theories suggest that autophagy is a protective factor and inhibits the process of apoptosis during the cytotoxicity reaction. In OS, Huang's PDT study indicated a totally different result. With the pretreatment of 3-methyladenine and chloroquine, two typical the inhibitors of autophagy, the apoptosis rate in MG-63 cells was significantly decreased, which reveals that PDT promotes the autophagy- dependent apoptosis in OS, which is different from the Tu's result mentioned before $[35,36]$. Although the gap exists between various tissues in different studies, the contradiction still suggests the complexity of balance between apoptosis and autophagy.

Necrosis is another important end point in cell reactions to cytotoxicity, determined by RIP3, a core protein in the process of necrosis [65]. Several studies have indicated that ROS from PDT can promote RIP3 combining with RIP1, producing the RIP1/ RIP3 necrosome complex, which further facilitates the accumulation of ROS, with MLKL, enhancing necrosis $[66,67]$. To date, the role of necrosis in PDT remains unclear, especially in OS. Coupienne reported that PDT induced with 5-ALA resulted in RIP3-dependent necrosis in U2OS, one of the typical OS cell lines [58]. This study reveals the necrosis activate the OS cell death in PDT, which has the possibility to be the novel therapy target of PDT in deep tumor. However, the specific processes in PDT-induced necrosis in OS and other deep tumor still need to be confirmed.

\section{Cell cycle arrest}

Cell cycle suppression is vital for the fission and proliferation of normal cells and cancer cells. It has been reported that, with activation by light irradiation, protoporphyrin IX increased expression of cyclin D1, inducing cell cycle disorder in the early and middle G1 phase [68]. Zorov's research indicated that the level of ROS can cause inhibition of p27 and activation of Cdk2, resulting in a transitional obstruction from the $\mathrm{G}_{0} / \mathrm{G}_{1}$ to $\mathrm{S}$ phase, which was suppressed by the expression of Bcl-2 [69]. Another study showed that a phthalocyanine PS could enhance the reduction of $S$ phase and cause arrest of the $\mathrm{G}_{2} / \mathrm{M}$ phase, which was dose-dependently increased by the PS. However, there was only a slight decrease in the $\mathrm{G}_{0} / \mathrm{G}_{1}$ phase with a high dose of PS $[70,71]$. This suggests that the $\mathrm{G}_{2} / \mathrm{M}$ phase transfer was blocked by a low dose of PS, while a higher dose also resulted in $\mathrm{G}_{0} / \mathrm{G}_{1}$ arrest. In contrast, Liu reported a different result in that PDT, leading to a delay in DNA synthesis and inhibiting the proliferation of lung adenocarcinoma, caused the S-phase arrest. This result was consistent with Tan's study and suggests an S-phase therapy target in PDT [72, 73].

In the Hiporfin-mediated PDT of OS, the PSs concentration-dependent cell cycle arrest at G2M was observed in the combination of PSs and irradiation, while no cell cycle alternation in the groups of single PSs or irradiation [14]. In the meantime, Lee proved that the G2M cell cycle arrest induced by PDT in OS was conducted in a p53-independent manner. On the other hand, the timeprocess in the induction process of cell cycle arrest was uncovered. The peak of PDT-induced G2M cell cycle arrest was around $16 \mathrm{~h}$ after irradiation while recovering after 24h [59]. This also indicates the importance of time selection in PDT. 


\section{Tumor vessel effects}

Tumor vessels are vital factors in the growth of neoplasms and tumors promote angiogenesis with multiple vessel growth factors [74]. Middelburg's results showed that vasoconstriction and the absence of small vessels and arterioles occurred in ALA- and PpIX-induced PDT in skin tissue and this acute vascular effect was induced rapidly, resulting in hemadostenosis and slower blood flow, causing nutritional deficiency and inhibition of proliferation [75-77]. This was consistent with a study in vivo, demonstrating a clear time-correlated decrease in CD31 after PDT [78]. Nevertheless, hypoxia induced by vessel disorders can cause activation of HIF-1, which stimulates the expression of VEGF and COX-2, promoting tumor angiogenesis. Thus, PDT may benefit from combination with HIF-1 inhibitors [79]. In addition to vasoconstriction, PDT alters the permeability and facilitates the concentration of other drugs in tumor tissue. Zhen proved that PDT directly damaged vascular endothelial cells, with ROS generation [80]. However, permeabilization commonly causes the absence of blood perfusion by high-dose PDT, such as stenosis or the occlusion of vessels. Thus, low-dose PDT will more effectively improve permeability [81].

\section{Immunogenic cell death}

Cancer cell death is a complex process and the death of different cells will cause divergence in the immune response; this is commonly separated into immunogenic versus non-immunogenic cell death (ICD vs. non-ICD). This difference results from various stimuli [82]. ICD has been shown to be another target in multiple therapeutic methods. Several studies have indicated that ICD has specific biomarkers, including calreticulin surface exposure (ecto-CALR), ATP secretion, and high-mobility group box 1 [83-85]. Activation of ICD depends on mature macrophages and dendritic cells (DCs), induced by CD91, which recognize and phagocytize calreticulin (CRT)positive cells [86]. Then, CTL cells will be activated by antigen presentation and kill the tumor in an immunespecific manner. ROS-dependent endoplasmic reticulum stress leads to translocation of CRT, which is the initial alteration in PDT-induced ICD $[87,88]$. This suggests the possibility of combining PDT and immunotherapies.

Multiple immune cells are involved in cell activation in the PDT-induced immune response. DCs initiate the process, which is also associated with the activation of Toll-like receptor 4 (TLR4) and the purinergic receptor P2rx7 [89, 90]. The essential stimulation function of HSP70 and the receptor CD91 has been reported in prostate cancer cell radiotherapy. With irradiation, HSP70 leaves the nucleus and activation of cytoplasmic and cell-surface expression occurs, enhancing antigen cross-presentation in the process of DC recognition [91]. Mature DCs are activated by multiple stimulating factors and present antigens to $T$ cells, inducing the secretion of various inflammatory factors and activation of $\gamma \delta \mathrm{T}$ cells and CTLs, which directly execute anti-tumor functions in ICD [82].

ICD induced by PDT has multiple precise regulatory points. The most important one, autophagy, has been reported as the key inhibitor in ICD. Abhishek reported that knockdown of ATG5, an autophagy-related protein, significantly enhanced the translocation of CRT and the expression of CD86/HLA-DR, showing the degree of DC activation in hypericin-based PDT. This was evidence that autophagy inhibited ICD in the pathway of suppressing ecto-CALR, followed by the suppression of T-cell activation [92]. Other studies have shown the promoting roles of necrosis and apoptosis in ICD, although the relative importance of necrosis and apoptosis is still a controversial issue [93, 94]. The viability ectonucleotidases, such as CD39 and CD79, which are related to the antigen-recognizing capabilities of immune cells, also stimulate the process of ICD. CD39 is an ATP transverter, transforming ATP to ADP or AMP, while CD73 transforms AMP to the immunosuppressive metabolite adenosine $[95,96]$. These two factors are the key points in ATP-based immune cell activation.

The studies in chemotherapy have revealed the possibility of ICD pathway in OS treatment. Kawano proved that the expression of HSP70 and CRT was increased significantly with the treatment doxorubicin and enhanced the activation of DC in nuclear factor (NF)$\kappa \mathrm{B}$ pathway and promoted the gathering and cytotoxicity of CD8+ T-lymphocytes in the tumor tissues [97]. In the PDT research of OS, the increase expression of HSP70 has been illuminated in MG-63 cell line, which conforms to the manifestation of ICD and suggests the prospect of ICD in PDT-induced OS treatment [98].

The cytotoxic effect of ROS in PDT has been illustrated at an explicit level. However, the specific pathways remain controversial. As discussed above, multiple pathways are involved in the process of PDTinduced cytotoxicity. Moreover, the anti-tumor effect relies on a combination of diverse pathways, subject to complex regulation. PDT suppresses tumor cells directly, leading to ROS-induced apoptosis and necrosis, while the activation of autophagy reverses the anti-tumor effects of PDT. At the same time, apoptosis and necrosis also stimulate the activation of DCs, which recognize PDT-induced antigens on the surfaces of tumor cells, promoting the maturation of CTLs and resulting in CTL-induced specific cellular immune responses. PDT-induced tumor vessel injury and cell cycle arrest also result in apoptosis in the tumor in PDT (Figure 4). 


\section{NOVEL STRATEGIES IN PDT OF OS}

\section{Modification of PSs}

\section{Nanotechnology}

Nanoparticles (NPs) has been developed rapidly, providing a revolutionary breakthrough in PDT [11]. The benefits of NPs in PDT include: 1) NPs can promote specific accumulation in tumor tissues, induced by the permeability and retention (EPR) effect, because of leaky tumor vessels [99]. 2) NPs of the appropriate size spend a longer time circulating in plasma with less elimination [100] and 3) less elimination in other organs leads to the reduction of cytotoxicity in other organs [101]. 4) NPs have a more stable complex in solution and plasma, with reduced sedimentation in tissues [11]. 5) NPs can be modified with various chemical groups, such as targeting molecules and condition-response molecules $[102,103]$.

Liposomes are a common in PS delivery. For example, liposome-encapsulated $\mathrm{ZnPc}$ showed a specific targeting effect and good modifiability in vitro [104]. NPs based on polymers are also popular carriers, with hydrophilic and hydrophobic termini [105]. The various side chains of polymeric micelles with diverse structures facilitate the connection of target molecules and other modifications [106, 107]. The mesoporous silicon is another nice carrier with high biocompatibility, which can improve the loading capacity significantly and inhibit the self-gathering in plasma $[49,108]$. Meanwhile, some metal materials are of nano size themselves and disperse stably in water, such as tin tungstate $\mathrm{NPs}$ and $\mathrm{TiO}_{2} \mathrm{NPs}$, which show stable states and long residual times in tumors $[109,110]$.

The studies of nanotechnology in OS are still in the initial stage. Shi' research reveals the nanostructured hydroxyapatite conducts the size-associated cytotoxicity

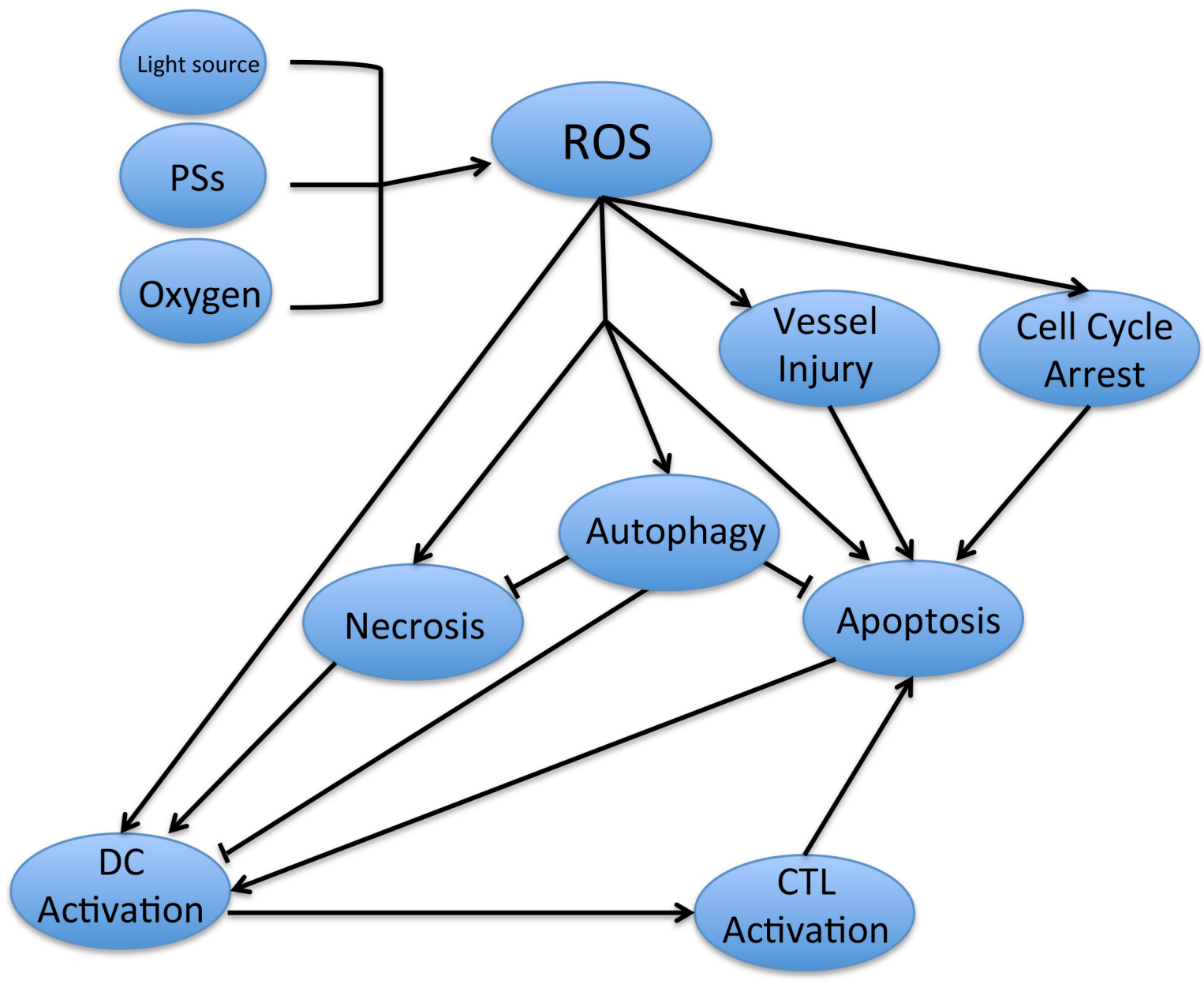

Figure 4: The relevant pathways involved in PDT-induced antitumor effect. The ROS is activated by the combination of light source, PSs and oxygen, which cause the necrosis, apoptosis and the activation of DCs in tumor cells. With the recognition of antigen on the surface of tumor cells, DCs activate the CTL and lead to the specific cellular immune to the tumor. At the same time, the ROS will promote the autophagy in cancer cells, which will reverse the cell death with the inhibition of necrosis and apoptosis. On the other hands, the tumor vessels injury and cell cycle arrest will also cause the apoptosis of cancer cells. 
to OS cell line [111]. Another special nanoparticle using in OS treatment is nano-selenium, which was proved by its anticancer effect in bone tumor while promoting the properties of healthy bone in the employment of Titanium coating with selenium nanoclusters [112]. However, NPs in PDT studies are rare in OS and more researches are required.

\section{Targeted therapy}

Beyond the EPR effect with NPs, conjugation of targeting molecules is also effective to promote the target-delivery in PDT. Multiple studies have focused on the RGD sequence, an amino acid sequence, as a target molecule in recent years, which links specifically with cell surface integrin [113]. In Yuan's research, RGD was used as a target on the surface of NP with the conjugation of
PEG, forming dendritic NPs. Various studies showed that this can effectively enhance the production of chlorin e6induced singlet oxygen because of higher uptake by the tumor [114]. Another type of targeted therapy involves conditional response-induced PSs, which are released at a specific location. Given the abnormal $\mathrm{pH}$ conditions in tumor tissue, a pH-responsive PS modification is the most common conditional response modification, leading to preferential accumulation of PSs in tumor tissues [115, 116].

There are still a few of bone-specificity targeting molecules in OS researches. An in vivo magnetic resonance imaging study revealed that alendronate-conjugated contrast agent showed higher enhancement in OS, suggesting a targeting effect of alendronate in OS tissue [117]. Moreover, alendronate can inhibit OS cells directly,

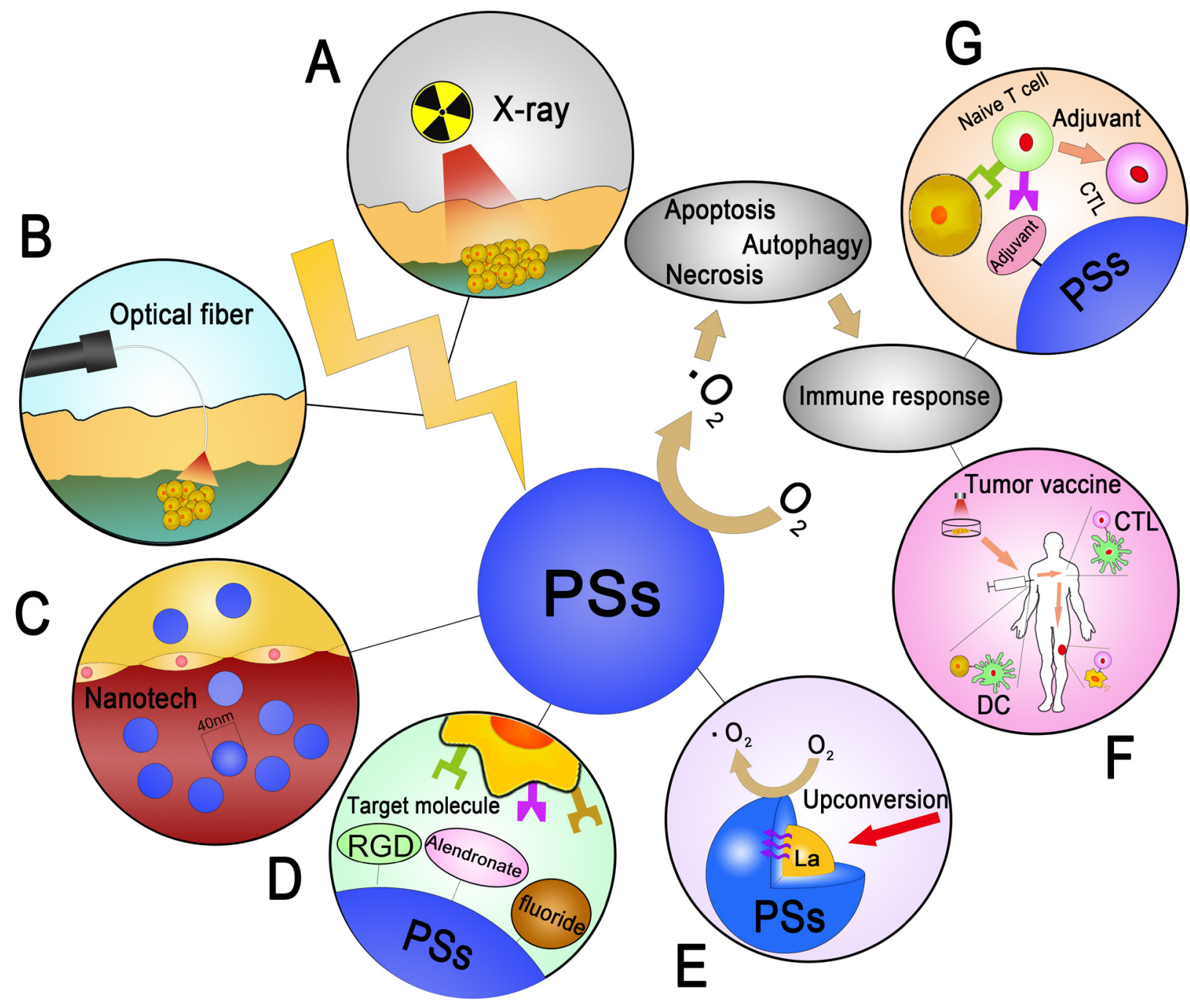

Figure 5: The summarization of seven feasible improvements to PDT in OS. A. The employment of X-ray, which has the high penetrating in various tissues B. Using the optical fiber as the conductor of laser in the skin, which avoid the epithelial tissue injury and lead to the cytotoxicity directly. C. Designing the PSs in a nano size to enhance the cycling time in body and gathering in tumor tissue induced by EPR effect. D. Combining with the target molecule and result to the gathering effect in tumor tissue. E. The combination of RE elements induced by upconversion with the core-shell structure of PSs. F. Utilization of tumor vaccine induced by PDT. G. Adjuvant- related CTL activation in PDT. 
with the activation of apoptosis and the suppression of angiogenesis in tumor tissues [118]. Considering the targeting of osteoporosis, alendronate has potential in targeted therapy in PDT, but the specific mechanism is needed [119]. Another potential target molecule is tetracycline, which can facilitate PLGA NP adsorption in hydroxyapatite in vitro and reduce distribution to other organs, such as the liver, lungs, and spleen, as well as promoting drug accumulation in the femur and tibia [120]. Fluoride also presents the possibility of bone targeting, as the same disorders with tetracycline in teeth and skeleton. ${ }^{18} \mathrm{~F}$, as a radiotracer, was shown to accumulate in a lung metastasis of an osteogenic sarcoma [121]. These results were consistent with Campanile's study, indicating bone remodeling and tumor targeting of ${ }^{18} \mathrm{~F}$-fluoride in PET imaging [122]. This suggests the possibility of bonetargeting fluoride-modified NPs in PDT.

\section{Upconversion effect}

The rare-earth (RE) element-induced luminescence upconversion emerged as a novel concept in material research, first characterized in 1958. UC nanoparticles (UCNPs) acts as energy transducers, transforming two or more low-energy photons to one higher-energy photon, and can potentially enhance PDT [123]. With this unique transduction effect, UCNPs can emit higher-energy-level light from irradiation with near-infrared light and activate the higher PS-induced photochemistry effects with lower irradiation energy in deep tissues, achieving a depth otherwise impenetrable with UV-visible light.

The researches of UCNPs have shown low toxicity and high biocompatibility in vitro and in vivo, which suggests the clinical use in OS treatment [124-127]. Of the various modifications of RE materials, the erbium-doped sodium yttrium fluoride ( $\mathrm{NaYF} 4: \mathrm{Er}^{3+}$ ) system is the most valuable in UCNP-induced PDT, along with ytterbiumand thulium-doped systems, which commonly use a coreshell structure [128-130]. Beyond the luminous energy transition, UCNP-linked PSs have shown good imaging performance. Zeng's research showed that tumor tissue exposed to $\mathrm{NaYF}_{4}$ : $\mathrm{Yb} /$ Er-based $\mathrm{Fe}_{3} \mathrm{O}_{4} \mathrm{NPs}$ as T2-weighted MRI contrast agents was significantly darker in vitro and in vivo and inhibition of MCF-7 and HeLa cells was seen with 980-nm laser irradiation [127].

\section{Improvements in light sources}

\section{X-rays}

With less soft tissue obstruction, X-rays have deep penetrability in various tissues except the skeletal system, which can reduce the obstruction of surface tissue [131]. Based on fluorescence resonance energy transfer, RE NPs can be stimulated with X-rays and transfer more energy to UV-vis luminescence processes, which may be suitable for the optimum absorption of PSs, activating ROS in deep tumor models [12]. Lanthanide-doped NPs show high-efficiency photon transition, as used commonly in X-ray-induced PDT. For example, Zou used $\mathrm{LaF}_{3}: \mathrm{Ce}^{3+}$ / DMSO/PPIX/PLGA microspheres, a novel RE material, showing significant oxidative stress, and mitochondrial and DNA injury [132]. It has reported that the combination of acridine orange and low-dose X-ray caused the cytocidal effect on mouse osteosarcoma, which revealed the possibility of PDT in OS therapy induced by X-ray [133]. However, the higher penetrability of X-rays also leads to injury of peripheral tissues. Thus, the high targetgathering capacities of PSs are quite important in X-rayinduced PDT.

\section{Optical fibers}

Optical fiber (OF) has a flexible structure featuring cladding and a core, which allows laser diffusion over a tortuous route because of multiple reflections within the fiber [134]. Moreover, the minor diameter of OFs facilitates puncturing through the skin and subcutaneous tissues with minimal invasion and reaching tumor tissues in deep tissue. OFs in PDT have been studied in endodontium infection [135, 136]. Furthermore, with the safe and effective transmission of laser energy, OFs provide the possibility of PDT in OS patients. But the decay of laser limits the usage of OFs. Thus, novel types of with high laser conductivity are important to advance OF-induced PDT in OS.

\section{Immunotherapy in PDT}

\section{Combination of an adjuvant and PDT}

The combination of a PS and an adjuvant can enhance the ICD-induced tumor antigen recognition and promote APC activation. Unmethylated $\mathrm{CpG}$, derived from bacterial extracts, is one type of oligodeoxynucleotide that has been demonstrated to activate pre-DCs directly and lead to the activation of NK and T cells [137]. Xia reported the combination of $\mathrm{CpG}$ and verteporfin, a benzoporphyrin-derived PS, in PDT research for breast cancer. The results showed a marked increase in the expression of MHC class II, CD80, and CD86, three biomarkers of DC maturation and activation, and inhibited tumor proliferation significantly in vivo [138]. Korbelik's group used two regimens, mycobacterium cell-wall extract (MCWE) and Bacillus Calmette-Guérin (BCG), as immune promoters. Both MCWE and BCG increased the percentage of tumor-free mice, while BCG inhibited the growth of tumor volume simultaneously [139, 140].

Recently, FDA has approved the mifamurtide in combination with postoperation or chemotherapy of high-grade non-metastatic OS patients, which is a novel immunoadjuvant in OS therapy [141]. Multiple clinical trials have proved the effectiveness of mifamurtide in OS treatment [142-144]. After intravenous injection, 
mifamurtide increases the expression of nucleotidebinding oligomerization domain 2 (NOD2) receptor in monocytes, dendritic cells, and macrophages, which activates the NF- $\mathrm{BB}$ pathway and secretion of various cytokines [141, 145]. As the enhancement of PDTinduced ICD in various malignancies, the combination of mifamurtide and PDT is targeted to two aspects: 1) the PDT-induced increasing of antigen expression in tumor and 2) the mifamurtide-induced activation of antigen presenting cells. However, it needs to be deeply researched in vitro and vivo.

\section{PDT-induced tumor vaccination}

With PDT pretreatment, tumor cell lysates show important systemic immunological effects [146]. Gollnick compared the different anti-tumor immune responses with various pretreatments. Pretreatment induced by PDT showed the highest immune responses and significantly inhibited tumor proliferation, versus freeze/thaw-induced or medium-induced pretreatment. This resulted in the activation of DCs and the secretion of IFN- $\gamma$ [147]. Therapeutic protocols for PDT-treated vaccination in squamous cell carcinoma have been established in Korbelik's lab [148, 149]. In the protocol, cancer cells were exposed to PSs in serum-free medium and the cells were used as a vaccine, injected subcutaneously in syngeneic mice after X-ray irradiation [146]. Further studies showed an acute-phase response with PDTinduced immune responses. The balance between CRT and HSP70 was responsible for this process, which occurred with glucocorticoids, while inhibitors of glucocorticoids abrogated the effect $[148,150]$.

\section{CONCLUSIONS AND PROSPECTS}

PDT has been discussed for a long time because of its cross-disciplines in tumor therapy. Many clinical trials have shown its usage in treating superficial tumors $[151,152]$. However, the limitations of PDT are obvious in treating deep tumors, especially OS. This review summarized the anti tumor mechanisms and recent progresses of PDT in deep tumor models, especially in OS. We also suggest some practical improvements that may lead to significant enhancement in PDT-induced OS therapies (Figure 5). In conclusion, PDT for OS is still its early stage. More researches are still needed on the mechanisms and applications of PDT in OS treatment.

\section{ACKNOWLEDGMENTS}

This study was supported by grant from the National Natural Science Foundation of China (NO. 81472504), National Natural Science Foundation of China (NO. 81401822) and the Science and Technology Planning Project of Zhejiang Province (NO. 2013C33231)

\section{CONFLICT OF INTEREST}

There is no conflict of interest.

\section{REFERENCES}

1. Ritter J, Bielack SS. Osteosarcoma. Ann Oncol. 2010; 21 Suppl 7:vii320-325.

2. Aponte-Tinao L, Ayerza MA, Muscolo DL, Farfalli GL. Survival, recurrence, and function after epiphyseal preservation and allograft reconstruction in osteosarcoma of the knee. Clin Orthop Relat Res. 2015; 473:1789-1796.

3. Anderson ME. Update on Survival in Osteosarcoma. Orthop Clin North Am. 2016; 47:283-292.

4. Ta HT, Dass CR, Choong PF, Dunstan DE. Osteosarcoma treatment: state of the art. Cancer Metastasis Rev. 2009; 28:247-263.

5. Tiwari A. Current concepts in surgical treatment of osteosarcoma. J Clin Orthop Trauma. 2012; 3:4-9.

6. Horie T, Ono K, Nishi H, Nagao K, Kinoshita M, Watanabe S, Kuwabara Y, Nakashima Y, Takanabe-Mori R, Nishi E, Hasegawa K, Kita T, Kimura T. Acute doxorubicin cardiotoxicity is associated with miR-146a-induced inhibition of the neuregulin-ErbB pathway. Cardiovasc Res. 2010; 87:656-664.

7. Isakoff MS, Bielack SS, Meltzer P, Gorlick R. Osteosarcoma: Current Treatment and a Collaborative Pathway to Success. J Clin Oncol. 2015; 33:3029-3035.

8. Canter RJ. Chemotherapy: Does Neoadjuvant or Adjuvant Therapy Improve Outcomes? Surg Oncol Clin N Am. 2016; 25:861-872.

9. Agostinis P, Berg K, Cengel KA, Foster TH, Girotti AW, Gollnick SO, Hahn SM, Hamblin MR, Juzeniene A, Kessel D, Korbelik M, Moan J, Mroz P, et al. Photodynamic therapy of cancer: an update. CA Cancer J Clin. 2011; 61:250-281.

10. St Denis TG, Hamblin MR. Synthesis, bioanalysis and biodistribution of photosensitizer conjugates for photodynamic therapy. Bioanalysis. 2013; 5:1099-1114.

11. Cheng L, Wang C, Feng L, Yang K and Liu Z. Functional nanomaterials for phototherapies of cancer. Chem Rev. 2014; 114:10869-10939.

12. Kamkaew A, Chen F, Zhan Y, Majewski RL, Cai W. Scintillating Nanoparticles as Energy Mediators for Enhanced Photodynamic Therapy. ACS Nano. 2016; 10:3918-3935.

13. Abrahamse H, Hamblin MR. New photosensitizers for photodynamic therapy. Biochem J. 2016; 473:347-364.

14. Sun M, Zhou C, Zeng H, Puebla-Osorio N, Damiani E, Chen J, Wang H, Li G, Yin F, Shan L, Zuo D, Liao Y, Wang Z, et al. Hiporfin-mediated photodynamic therapy in preclinical treatment of osteosarcoma. Photochem Photobiol. 2015; 91:533-544.

15. Meier D, Campanile C, Botter SM, Born W, Fuchs 
B. Cytotoxic efficacy of photodynamic therapy in osteosarcoma cells in vitro. J Vis Exp. 2014.

16. Reidy K, Campanile C, Muff R, Born W, Fuchs B. mTHPC-mediated photodynamic therapy is effective in the metastatic human 143B osteosarcoma cells. Photochem Photobiol. 2012; 88:721-727.

17. Peng Q, Berg K, Moan J, Kongshaug M, Nesland JM. 5-Aminolevulinic acid-based photodynamic therapy: principles and experimental research. Photochem Photobiol. 1997; 65:235-251.

18. White B, Rossi V, Baugher PJ. Aminolevulinic AcidMediated Photodynamic Therapy Causes Cell Death in MG-63 Human Osteosarcoma Cells. Photomed Laser Surg. 2016; 34:400-405.

19. Huang $\mathrm{Y}, \mathrm{Xu}$ G, Peng $\mathrm{Y}$, Lin $\mathrm{H}$, Zheng $\mathrm{X}$, Xie $\mathrm{M}$. Zinc phthalocyanine tetrasulfonate $(\mathrm{ZnPcS} 4)$ : a new photosensitizer for photodynamic therapy in choroidal neovascularization. J Ocul Pharmacol Ther. 2007; 23:377386.

20. Ongarora BG, Hu X, Verberne-Sutton SD, Garno JC, Vicente MG. Syntheses and Photodynamic Activity of Pegylated Cationic Zn(II)-Phthalocyanines in HEp2 Cells. Theranostics. 2012; 2:850-870.

21. Feuser PE, Gaspar PC, Jacques AV, Tedesco AC, dos Santos Silva MC, Ricci-Junior E, Sayer C, de Araujo $\mathrm{PH}$. Synthesis of $\mathrm{ZnPc}$ loaded poly(methyl methacrylate) nanoparticles via miniemulsion polymerization for photodynamic therapy in leukemic cells. Mater Sci Eng C Mater Biol Appl. 2016; 60:458-466.

22. Gao W, Wang Z, Lv L, Yin D, Chen D, Han Z, Ma Y, Zhang M, Yang M, Gu Y. Photodynamic Therapy Induced Enhancement of Tumor Vasculature Permeability Using an Upconversion Nanoconstruct for Improved Intratumoral Nanoparticle Delivery in Deep Tissues. Theranostics. 2016; 6:1131-1144.

23. Jin CS, Cui L, Wang F, Chen J, Zheng G. Targetingtriggered porphysome nanostructure disruption for activatable photodynamic therapy. Adv Healthc Mater. 2014; 3:1240-1249.

24. Allison RR. Photodynamic therapy: oncologic horizons. Future Oncol. 2014; 10:123-124.

25. Dolmans DE, Fukumura D, Jain RK. Photodynamic therapy for cancer. Nat Rev Cancer. 2003; 3:380-387.

26. Allison RR, Mota HC, Sibata CH. Clinical PD/PDT in North America: An historical review. Photodiagnosis Photodyn Ther. 2004; 1:263-277.

27. Tsai SR, Yin R, Huang YY, Sheu BC, Lee SC, Hamblin MR. Low-level light therapy potentiates NPe6-mediated photodynamic therapy in a human osteosarcoma cell line via increased ATP. Photodiagnosis Photodyn Ther. 2015; 12:123-130.

28. Guan J, Lai X, Wang X, Leung AW, Zhang H, Xu C. Photodynamic action of methylene blue in osteosarcoma cells in vitro. Photodiagnosis Photodyn Ther. 2014; 11:13-
19.

29. Foote CS. Definition of type I and type II photosensitized oxidation. Photochem Photobiol. 1991; 54:659.

30. Oniszczuk A, Wojtunik-Kulesza KA, Oniszczuk T, Kasprzak K. The potential of photodynamic therapy (PDT)Experimental investigations and clinical use. Biomed Pharmacother. 2016; 83:912-929.

31. Romiszewska A, Nowak-Stepniowska A. [Photodynamic reaction and oxidative stress - influence of the photodynamic effect on the activity antioxidant enzymes]. Postepy Biochem. 2014; 60:355-364.

32. Ogbodu RO, Nyokong T. The effect of ascorbic acid on the photophysical properties and photodynamic therapy activities of zinc phthalocyanine-single walled carbon nanotube conjugate on MCF-7 cancer cells. Spectrochim Acta A Mol Biomol Spectrosc. 2015; 151:174-183.

33. Cheng Y, Cheng H, Jiang C, Qiu X, Wang K, Huan W, Yuan A, Wu J, Hu Y. Perfluorocarbon nanoparticles enhance reactive oxygen levels and tumour growth inhibition in photodynamic therapy. Nat Commun. 2015; $6: 8785$.

34. Li KT, Chen Q, Wang DW, Duan QQ, Tian S, He JW, Ou YS, Bai DQ. Mitochondrial pathway and endoplasmic reticulum stress participate in the photosensitizing effectiveness of AE-PDT in MG63 cells. Cancer Med. 2016; 5:3186-3193.

35. Tu P, Huang Q, Ou Y, Du X, Li K, Tao Y, Yin H. Aloeemodin-mediated photodynamic therapy induces autophagy and apoptosis in human osteosarcoma cell line MG63 through the ROS/JNK signaling pathway. Oncol Rep. 2016; 35:3209-3215.

36. Huang Q, Ou YS, Tao Y, Yin H, Tu PH. Apoptosis and autophagy induced by pyropheophorbide-alpha methyl ester-mediated photodynamic therapy in human osteosarcoma MG-63 cells. Apoptosis. 2016; 21:749-760.

37. Matsubara T, Diresta GR, Kakunaga S, Li D, Healey JH. Additive Influence of Extracellular pH, Oxygen Tension, and Pressure on Invasiveness and Survival of Human Osteosarcoma Cells. Front Oncol. 2013; 3:199.

38. Cheung KK, Chan JY, Fung KP. Antiproliferative effect of pheophorbide a-mediated photodynamic therapy and its synergistic effect with doxorubicin on multiple drugresistant uterine sarcoma cell MES-SA/Dx5. Drug Chem Toxicol. 2013; 36:474-483.

39. Zeng L, Pan Y, Tian Y, Wang X, Ren W, Wang S, Lu G, Wu A. Doxorubicin-loaded NaYF4:Yb/Tm-TiO2 inorganic photosensitizers for NIR-triggered photodynamic therapy and enhanced chemotherapy in drug-resistant breast cancers. Biomaterials. 2015; 57:93-106.

40. Yamauchi M, Honda N, Hazama H, Tachikawa S, Nakamura H, Kaneda Y, Awazu K. A novel photodynamic therapy for drug-resistant prostate cancer cells using porphyrus envelope as a novel photosensitizer. Photodiagnosis Photodyn Ther. 2014; 11:48-54. 
41. Lindsay J, Esposti MD, Gilmore AP. Bcl-2 proteins and mitochondria - specificity in membrane targeting for death. Biochim Biophys Acta. 2011; 1813:532-539.

42. Goler-Baron V, Assaraf YG. Overcoming multidrug resistance via photodestruction of ABCG2-rich extracellular vesicles sequestering photosensitive chemotherapeutics. PLoS One. 2012; 7:e35487.

43. Chen B, Pogue BW, Hoopes PJ, Hasan T. Combining vascular and cellular targeting regimens enhances the efficacy of photodynamic therapy. Int J Radiat Oncol Biol Phys. 2005; 61:1216-1226.

44. Barathan M, Mariappan V, Shankar EM, Abdullah BJ, Goh KL, Vadivelu J. Hypericin-photodynamic therapy leads to interleukin- 6 secretion by HepG2 cells and their apoptosis via recruitment of $\mathrm{BH} 3$ interacting-domain death agonist and caspases. Cell Death Dis. 2013; 4:e697.

45. Snyder JW, Greco WR, Bellnier DA, Vaughan L, Henderson BW. Photodynamic therapy: a means to enhanced drug delivery to tumors. Cancer Res. 2003; 63:8126-8131.

46. Wang D, Wang T, Liu J, Yu H, Jiao S, Feng B, Zhou F, Fu Y, Yin Q, Zhang P, Zhang Z, Zhou Z, Li Y. AcidActivatable Versatile Micelleplexes for PD-L1 BlockadeEnhanced Cancer Photodynamic Immunotherapy. Nano Lett. 2016; 16:5503-5513.

47. Kusuzaki K, Minami G, Takeshita H, Murata H, Hashiguchi S, Nozaki T, Ashihara T, Hirasawa Y. Photodynamic inactivation with acridine orange on a multidrug-resistant mouse osteosarcoma cell line. Jpn J Cancer Res. 2000; 91:439-445.

48. Zeng L, Ren W, Xiang L, Zheng J, Chen B, Wu A. Multifunctional Fe3O4-TiO2 nanocomposites for magnetic resonance imaging and potential photodynamic therapy. Nanoscale. 2013; 5:2107-2113.

49. Ma X, Qu Q, Zhao Y. Targeted delivery of 5-aminolevulinic acid by multifunctional hollow mesoporous silica nanoparticles for photodynamic skin cancer therapy. ACS Appl Mater Interfaces. 2015; 7:10671-10676.

50. Hirohara S, Oka C, Totani M, Obata M, Yuasa J, Ito H, Tamura M, Matsui H, Kakiuchi K, Kawai T, Kawaichi M, Tanihara M. Synthesis, Photophysical Properties, and Biological Evaluation of trans-Bisthioglycosylated Tetrakis(fluorophenyl)chlorin for Photodynamic Therapy. J Med Chem. 2015; 58:8658-8670.

51. Muhanna N, Cui L, Chan H, Burgess L, Jin CS, MacDonald TD, Huynh E, Wang F, Chen J, Irish JC, Zheng G. Multimodal Image-Guided Surgical and Photodynamic Interventions in Head and Neck Cancer: From Primary Tumor to Metastatic Drainage. Clin Cancer Res. 2016; 22:961-970.

52. Vera RE, Lamberti MJ, Rivarola VA, Rumie Vittar NB. Developing strategies to predict photodynamic therapy outcome: the role of melanoma microenvironment. Tumour Biol. 2015; 36:9127-9136.
53. Hu J, Tang Y, Elmenoufy AH, Xu H, Cheng Z, Yang X. Nanocomposite-Based Photodynamic Therapy Strategies for Deep Tumor Treatment. Small. 2015; 11:5860-5887.

54. Vijayaraghavan P, Vankayala R, Chiang CS, Sung HW, Hwang KC. Complete destruction of deep-tissue buried tumors via combination of gene silencing and gold nanoechinus-mediated photodynamic therapy. Biomaterials. 2015; 62:13-23.

55. Fotia C, Avnet S, Kusuzaki K, Roncuzzi L, Baldini N. Acridine Orange is an Effective Anti-Cancer Drug that Affects Mitochondrial Function in Osteosarcoma Cells. Curr Pharm Des. 2015; 21:4088-4094.

56. Satonaka H, Kusuzaki K, Akeda K, Tsujii M, Iino T, Uemura T, Matsubara T, Nakamura T, Asanuma K, Matsumine A, Sudo A. Acridine orange inhibits pulmonary metastasis of mouse osteosarcoma. Anticancer Res. 2011; 31:4163-4168.

57. Yanase S, Nomura J, Matsumura Y, Nagata T, Fujii T, Tagawa T. Synergistic interaction of 5-aminolevulinic acid-based photodynamic therapy with simultaneous hyperthermia in an osteosarcoma tumor model. Int J Oncol. 2006; 29:365-373.

58. Coupienne I, Fettweis G, Piette J. RIP3 expression induces a death profile change in U2OS osteosarcoma cells after 5-ALA-PDT. Lasers Surg Med. 2011; 43:557-564.

59. Lee HB, Ho AS and Teo SH. p53 Status does not affect photodynamic cell killing induced by hypericin. Cancer Chemother Pharmacol. 2006; 58:91-98.

60. Matsubara T, Kusuzaki K, Matsumine A, Satonaka H, Shintani K, Nakamura T, Uchida A. Methylene blue in place of acridine orange as a photosensitizer in photodynamic therapy of osteosarcoma. In Vivo. 2008; 22:297-303.

61. Scherz-Shouval R, Shvets E, Fass E, Shorer H, Gil L and Elazar Z. Reactive oxygen species are essential for autophagy and specifically regulate the activity of Atg4. EMBO J. 2007; 26:1749-1760.

62. Duan P, Hu C, Quan C, Yu T, Zhou W, Yuan M, Shi Y, Yang K. 4-Nonylphenol induces apoptosis, autophagy and necrosis in Sertoli cells: Involvement of ROS-mediated AMPK/AKT-mTOR and JNK pathways. Toxicology. 2016; 341-343:28-40.

63. Li X, Zhu F, Jiang J, Sun C, Wang X, Shen M, Tian R, Shi C, Xu M, Peng F, Guo X, Wang M, Qin R. Synergistic antitumor activity of withaferin A combined with oxaliplatin triggers reactive oxygen species-mediated inactivation of the PI3K/AKT pathway in human pancreatic cancer cells. Cancer Lett. 2015; 357:219-230.

64. Shao FY, Du ZY, Ma DL, Chen WB, Fu WY, Ruan BB, Rui W, Zhang JX, Wang S, Wong NS, Xiao H, Li MM, Liu X, et al. B5, a thioredoxin reductase inhibitor, induces apoptosis in human cervical cancer cells by suppressing the thioredoxin system, disrupting mitochondrion-dependent pathways and triggering autophagy. Oncotarget. 2015; 6:30939-30956. doi: 10.18632/oncotarget.5132. 
65. Ramachandran A, McGill MR, Xie Y, Ni HM, Ding WX, Jaeschke H. Receptor interacting protein kinase 3 is a critical early mediator of acetaminophen-induced hepatocyte necrosis in mice. Hepatology. 2013; 58:20992108 .

66. Schenk B, Fulda S. Reactive oxygen species regulate Smac mimetic/TNFalpha-induced necroptotic signaling and cell death. Oncogene. 2015; 34:5796-5806.

67. Frame FM, Savoie H, Bryden F, Giuntini F, Mann VM, Simms MS, Boyle RW, Maitland NJ. Mechanisms of growth inhibition of primary prostate epithelial cells following gamma irradiation or photodynamic therapy include senescence, necrosis, and autophagy, but not apoptosis. Cancer Med. 2016; 5:61-73.

68. Blazquez-Castro A, Carrasco E, Calvo MI, Jaen P, Stockert JC, Juarranz A, Sanz-Rodriguez F, Espada J. Protoporphyrin IX-dependent photodynamic production of endogenous ROS stimulates cell proliferation. Eur J Cell Biol. 2012; 91:216-223.

69. Zorov DB, Juhaszova M, Sollott SJ. Mitochondrial reactive oxygen species (ROS) and ROS-induced ROS release. Physiol Rev. 2014; 94:909-950.

70. Shao J, Xue J, Dai Y, Liu H, Chen N, Jia L, Huang J. Inhibition of human hepatocellular carcinoma HepG2 by phthalocyanine photosensitiser PHOTOCYANINE: ROS production, apoptosis, cell cycle arrest. Eur J Cancer. 2012; 48:2086-2096.

71. Vantieghem A, Xu Y, Assefa Z, Piette J, Vandenheede JR, Merlevede W, De Witte PA, Agostinis P. Phosphorylation of Bcl-2 in G2/M phase-arrested cells following photodynamic therapy with hypericin involves a CDK1mediated signal and delays the onset of apoptosis. J Biol Chem. 2002; 277:37718-37731.

72. Liu J, Zheng L, Li Y, Zhang Z, Zhang L, Shen L, Zhang X, Qiao H. Effect of DTPP-mediated photodynamic therapy on cell morphology, viability, cell cycle, and cytotoxicity in a murine lung adenocarcinoma cell line. Lasers Med Sci. 2015; 30:181-191.

73. Tan H, Gao S, Zhuang Y, Dong Y, Guan W, Zhang K, Xu J, Cui J. R-Phycoerythrin Induces SGC-7901 Apoptosis by Arresting Cell Cycle at S Phase. Mar Drugs. 2016; 14.

74. Cook KM, Figg WD. Angiogenesis inhibitors: current strategies and future prospects. CA Cancer J Clin. 2010; 60:222-243.

75. Middelburg TA, de Bruijn HS, Tettero L, van der Ploeg van den Heuvel A, Neumann HA, de Haas ER, Robinson DJ. Topical hexylaminolevulinate and aminolevulinic acid photodynamic therapy: complete arteriole vasoconstriction occurs frequently and depends on protoporphyrin IX concentration in vessel wall. J Photochem Photobiol B. 2013; 126:26-32.

76. Middelburg TA, de Vijlder HC, de Bruijn HS, van der Ploeg-van den Heuvel A, Neumann HA, de Haas ER, Robinson DJ. Topical photodynamic therapy using different porphyrin precursors leads to differences in vascular photosensitization and vascular damage in normal mouse skin. Photochem Photobiol. 2014; 90:896-902.

77. van Leeuwen-van Zaane F, de Bruijn HS, van der Ploeg-van den Heuvel A, Sterenborg HJ, Robinson DJ. The effect of fluence rate on the acute response of vessel diameter and red blood cell velocity during topical 5-aminolevulinic acid photodynamic therapy. Photodiagnosis Photodyn Ther. 2014; 11:71-81.

78. Choi J, Kim WJ, Park SW, Xu L, Kim SH, Min HS, Kwon GY, Cho CH, Kim S, Choi TH. Photodynamic therapy suppresses tumor growth in an in vivo model of human hemangioma. Arch Dermatol Res. 2014; 306:81-91.

79. Weijer R, Broekgaarden M, Krekorian M, Alles LK, van Wijk AC, Mackaaij C, Verheij J, van der Wal AC, van Gulik TM, Storm G, Heger M. Inhibition of hypoxia inducible factor 1 and topoisomerase with acriflavine sensitizes perihilar cholangiocarcinomas to photodynamic therapy. Oncotarget. 2016; 7:3341-3356. doi: 10.18632/ oncotarget.6490.

80. Zhen Z, Tang W, Chuang YJ, Todd T, Zhang W, Lin X, Niu G, Liu G, Wang L, Pan Z, Chen X, Xie J. Tumor vasculature targeted photodynamic therapy for enhanced delivery of nanoparticles. ACS Nano. 2014; 8:6004-6013.

81. Wang Y, Gonzalez M, Cheng C, Haouala A, Krueger T, Peters S, Decosterd LA, van den Bergh H, Perentes JY, Ris HB, Letovanec I, Debefve E. Photodynamic induced uptake of liposomal doxorubicin to rat lung tumors parallels tumor vascular density. Lasers Surg Med. 2012; 44:318-324.

82. Kroemer G, Galluzzi L, Kepp O, Zitvogel L. Immunogenic cell death in cancer therapy. Annu Rev Immunol. 2013; 31:51-72.

83. Obeid M, Tesniere A, Ghiringhelli F, Fimia GM, Apetoh L, Perfettini JL, Castedo M, Mignot G, Panaretakis T, Casares N, Metivier D, Larochette N, van Endert P, et al. Calreticulin exposure dictates the immunogenicity of cancer cell death. Nat Med. 2007; 13:54-61.

84. Martins I, Wang Y, Michaud M, Ma Y, Sukkurwala AQ, Shen S, Kepp O, Metivier D, Galluzzi L, Perfettini JL, Zitvogel L, Kroemer G. Molecular mechanisms of ATP secretion during immunogenic cell death. Cell Death Differ. 2014; 21:79-91.

85. Werthmoller N, Frey B, Wunderlich R, Fietkau R, Gaipl US. Modulation of radiochemoimmunotherapy-induced B16 melanoma cell death by the pan-caspase inhibitor zVAD-fmk induces anti-tumor immunity in a HMGB1-, nucleotide- and T-cell-dependent manner. Cell Death Dis. 2015; 6:e1761.

86. Gardai SJ, McPhillips KA, Frasch SC, Janssen WJ, Starefeldt A, Murphy-Ullrich JE, Bratton DL, Oldenborg PA, Michalak M, Henson PM. Cell-surface calreticulin initiates clearance of viable or apoptotic cells through transactivation of LRP on the phagocyte. Cell. 2005; 123:321334. 
87. Li D, Li L, Li P, Li Y, Chen X. Apoptosis of HeLa cells induced by a new targeting photosensitizer-based PDT via a mitochondrial pathway and ER stress. Onco Targets Ther. 2015; 8:703-711.

88. Garg AD, Agostinis P. ER stress, autophagy and immunogenic cell death in photodynamic therapy-induced anti-cancer immune responses. Photochem Photobiol Sci. 2014; 13:474-487.

89. Ghiringhelli F, Apetoh L, Tesniere A, Aymeric L, Ma Y, Ortiz C, Vermaelen K, Panaretakis T, Mignot G, Ullrich E, Perfettini JL, Schlemmer F, Tasdemir E, et al. Activation of the NLRP3 inflammasome in dendritic cells induces IL1beta-dependent adaptive immunity against tumors. Nat Med. 2009; 15:1170-1178.

90. Apetoh L, Ghiringhelli F, Tesniere A, Obeid M, Ortiz C, Criollo A, Mignot G, Maiuri MC, Ullrich E, Saulnier P, Yang H, Amigorena S, Ryffel B, et al. Toll-like receptor 4-dependent contribution of the immune system to anticancer chemotherapy and radiotherapy. Nat Med. 2007; 13:1050-1059.

91. Salimu J, Spary LK, Al-Taei S, Clayton A, Mason MD, Staffurth J, Tabi Z. Cross-Presentation of the Oncofetal Tumor Antigen 5T4 from Irradiated Prostate Cancer Cells-A Key Role for Heat-Shock Protein 70 and Receptor CD91. Cancer Immunol Res. 2015; 3:678-688.

92. Garg AD, Dudek AM, Ferreira GB, Verfaillie T, Vandenabeele P, Krysko DV, Mathieu C, Agostinis P. ROS-induced autophagy in cancer cells assists in evasion from determinants of immunogenic cell death. Autophagy. 2013; 9:1292-1307.

93. Shaif-Muthana M, McIntyre C, Sisley K, Rennie I, Murray A. Dead or alive: immunogenicity of human melanoma cells when presented by dendritic cells. Cancer Res. 2000; 60:6441-6447.

94. Zitvogel L, Casares N, Pequignot MO, Chaput N, Albert ML, Kroemer G. Immune response against dying tumor cells. Adv Immunol. 2004; 84:131-179.

95. d'Almeida SM, Kauffenstein G, Roy C, Basset L, Papargyris L, Henrion D, Catros V, Ifrah N, Descamps P, Croue A, Jeannin P, Gregoire M, Delneste Y, Tabiasco J. The ecto-ATPDase CD39 is involved in the acquisition of the immunoregulatory phenotype by M-CSF-macrophages and ovarian cancer tumor-associated macrophages: Regulatory role of IL-27. Oncoimmunology. 2016; 5:e1178025.

96. Stagg J, Beavis PA, Divisekera U, Liu MC, Moller A, Darcy PK, Smyth MJ. CD73-deficient mice are resistant to carcinogenesis. Cancer Res. 2012; 72:2190-2196.

97. Kawano M, Tanaka K, Itonaga I, Iwasaki T, Miyazaki M, Ikeda S, Tsumura H. Dendritic cells combined with doxorubicin induces immunogenic cell death and exhibits antitumor effects for osteosarcoma. Oncol Lett. 2016; 11:2169-2175.

98. Yanase S, Nomura J, Matsumura Y, Nagai K, Kinoshita M, Nakanishi H, Ohnishi Y, Tokuda T, Tagawa $T$.
Enhancement of the effect of 5-aminolevulinic acid-based photodynamic therapy by simultaneous hyperthermia. Int $\mathrm{J}$ Oncol. 2005; 27:193-201.

99. Guix M, Mayorga-Martinez CC, Merkoci A. Nano/ micromotors in (bio)chemical science applications. Chem Rev. 2014; 114:6285-6322.

100. Nishiyama N, Okazaki S, Cabral H, Miyamoto M, Kato Y, Sugiyama Y, Nishio K, Matsumura Y, Kataoka K. Novel cisplatin-incorporated polymeric micelles can eradicate solid tumors in mice. Cancer Res. 2003; 63:8977-8983.

101. Uchino H, Matsumura Y, Negishi T, Koizumi F, Hayashi T, Honda T, Nishiyama N, Kataoka K, Naito S, Kakizoe T. Cisplatin-incorporating polymeric micelles (NC-6004) can reduce nephrotoxicity and neurotoxicity of cisplatin in rats. Br J Cancer. 2005; 93:678-687.

102. Liu P, Sun L, Zhou DS, Zhang P, Wang YH, Li D, Li QH, Feng RJ. Retraction: Development of Alendronateconjugated Poly (lactic-co-glycolic acid)-Dextran Nanoparticles for Active Targeting of Cisplatin in Osteosarcoma. Sci Rep. 2016; 6:31938.

103. Dong Z, Feng L, Zhu W, Sun X, Gao M, Zhao H, Chao Y, Liu Z. CaCO3 nanoparticles as an ultra-sensitive tumor$\mathrm{pH}$-responsive nanoplatform enabling real-time drug release monitoring and cancer combination therapy. Biomaterials. 2016; 110:60-70.

104. Broekgaarden M, van Vught R, Oliveira S, Roovers RC, van Bergen en Henegouwen PM, Pieters RJ, Van Gulik TM, Breukink E, Heger M. Site-specific conjugation of single domain antibodies to liposomes enhances photosensitizer uptake and photodynamic therapy efficacy. Nanoscale. 2016; 8:6490-6494.

105. Croy SR, Kwon GS. Polymeric micelles for drug delivery. Curr Pharm Des. 2006; 12:4669-4684.

106. Hung HI, Klein OJ, Peterson SW, Rokosh SR, Osseiran S, Nowell NH, Evans CL. PLGA nanoparticle encapsulation reduces toxicity while retaining the therapeutic efficacy of EtNBS-PDT in vitro. Sci Rep. 2016; 6:33234.

107. $\mathrm{Ku}$ EB, Lee DJ, Na K, Choi SW, Youn YS, Bae SK, Oh KT, Lee ES. pH-Responsive globular poly(ethylene glycol) for photodynamic tumor therapy. Colloids Surf B Biointerfaces. 2016; 148:173-180.

108. Teng IT, Chang YJ, Wang LS, Lu HY, Wu LC, Yang CM, Chiu CC, Yang CH, Hsu SL, Ho JA. Phospholipidfunctionalized mesoporous silica nanocarriers for selective photodynamic therapy of cancer. Biomaterials. 2013; 34:7462-7470.

109. Seidl C, Ungelenk J, Zittel E, Bergfeldt T, Sleeman JP, Schepers U, Feldmann C. Tin Tungstate Nanoparticles: A Photosensitizer for Photodynamic Tumor Therapy. ACS Nano. 2016; 10:3149-3157.

110. Moosavi MA, Sharifi M, Ghafary SM, Mohammadalipour Z, Khataee A, Rahmati M, Hajjaran S, Los MJ, Klonisch T, Ghavami S. Photodynamic N-TiO2 Nanoparticle Treatment Induces Controlled ROS-mediated Autophagy and Terminal 
Differentiation of Leukemia Cells. Sci Rep. 2016; 6:34413.

111. Shi Z, Huang X, Liu B, Tao H, Cai Y, Tang R. Biological response of osteosarcoma cells to size-controlled nanostructured hydroxyapatite. J Biomater Appl. 2010; 25:19-37.

112. Tran PA, Sarin L, Hurt RH, Webster TJ. Titanium surfaces with adherent selenium nanoclusters as a novel anticancer orthopedic material. J Biomed Mater Res A. 2010; 93:14171428.

113. Ruoslahti E, Pierschbacher MD. New perspectives in cell adhesion: RGD and integrins. Science. 1987; 238:491-497.

114. Yuan A, Yang B, Wu J, Hu Y, Ming X. Dendritic nanoconjugates of photosensitizer for targeted photodynamic therapy. Acta Biomater. 2015; 21:63-73.

115. Liu L, Fu L, Jing T, Ruan Z, Yan L. pH-Triggered Polypeptides Nanoparticles for Efficient BODIPY ImagingGuided Near Infrared Photodynamic Therapy. ACS Appl Mater Interfaces. 2016; 8:8980-8990.

116. Yao X, Chen L, Chen X, Xie Z, Ding J, He C, Zhang J, Chen X.pH-responsive metallo-supramolecular nanogel for synergistic chemo-photodynamic therapy. Acta Biomater. 2015; 25:162-171.

117. Ge P, Sheng F, Jin Y, Tong L, Du L, Zhang L, Tian N, Li G. Magnetic resonance imaging of osteosarcoma using a bis(alendronate)-based bone-targeted contrast agent. Biomed Pharmacother. 2016; 84:423-429.

118. Ohba T, Cates JM, Cole HA, Slosky DA, Haro H, Ichikawa J, Ando T, Schwartz HS, Schoenecker JG. Pleiotropic effects of bisphosphonates on osteosarcoma. Bone. 2014; 63:110-120

119. McClung M, Clemmesen B, Daifotis A, Gilchrist NL, Eisman J, Weinstein RS, Fuleihan G el-H, Reda C, Yates AJ, Ravn P. Alendronate prevents postmenopausal bone loss in women without osteoporosis. A double-blind, randomized, controlled trial. Alendronate Osteoporosis Prevention Study Group. Ann Intern Med. 1998; 128:253261.

120. Wang H, Liu J, Tao S, Chai G, Wang J, Hu FQ, Yuan H. Tetracycline-grafted PLGA nanoparticles as bone-targeting drug delivery system. Int J Nanomedicine. 2015; 10:56715685 .

121. Woodbury DH, Beierwaltes WH. Fluorine-18 uptake and localization in soft tissue deposits of osteogenic sarcoma in rat and man. J Nucl Med. 1967; 8:646-651.

122. Campanile C, Arlt MJ, Kramer SD, Honer M, Gvozdenovic A, Brennecke P, Fischer CR, Sabile AA, Muller A, Ametamey SM, Born W, Schibli R, Fuchs B. Characterization of different osteosarcoma phenotypes by PET imaging in preclinical animal models. J Nucl Med. 2013; 54:1362-1368.

123. Wang HQ, Batentschuk M, Osvet A, Pinna L, Brabec CJ. Rare-earth ion doped up-conversion materials for photovoltaic applications. Adv Mater. 2011; 23:2675-2680.
124. Nyk M, Kumar R, Ohulchanskyy TY, Bergey EJ, Prasad PN. High contrast in vitro and in vivo photoluminescence bioimaging using near infrared to near infrared upconversion in $\mathrm{Tm} 3+$ and $\mathrm{Yb} 3+$ doped fluoride nanophosphors. Nano Lett. 2008; 8:3834-3838.

125. Du B, Han S, Zhao F, Lim KH, Xi H, Su X, Yao H, Zhou J. A smart upconversion-based light-triggered polymer for synergetic chemo-photodynamic therapy and dual-modal MR/UCL imaging. Nanomedicine. 2016.

126. Li H, Song S, Wang W, Chen K. In vitro photodynamic therapy based on magnetic-luminescent Gd2O3:Yb,Er nanoparticles with bright three-photon up-conversion fluorescence under near-infrared light. Dalton Trans. 2015; 44:16081-16090.

127. Zeng L, Luo L, Pan Y, Luo S, Lu G, Wu A. In vivo targeted magnetic resonance imaging and visualized photodynamic therapy in deep-tissue cancers using folic acid-functionalized superparamagnetic-upconversion nanocomposites. Nanoscale. 2015; 7:8946-8954.

128. Park YI, Kim HM, Kim JH, Moon KC, Yoo B, Lee KT, Lee N, Choi Y, Park W, Ling D, Na K, Moon WK, Choi $\mathrm{SH}$, et al. Theranostic probe based on lanthanide-doped nanoparticles for simultaneous in vivo dual-modal imaging and photodynamic therapy. Adv Mater. 2012; 24:57555761.

129. Chatterjee DK and Yong Z. Upconverting nanoparticles as nanotransducers for photodynamic therapy in cancer cells. Nanomedicine (Lond). 2008; 3:73-82.

130. Mi C, Wu J, Yang Y, Han B, Wei J. Efficient upconversion luminescence from Ba5Gd8Zn4O21: $\mathrm{Yb}(3+), \operatorname{Er}(3+)$ based on a demonstrated cross-relaxation process. Sci Rep. 2016; 6:22545.

131. Pushie MJ, Pickering IJ, Korbas M, Hackett MJ, George GN. Elemental and chemically specific X-ray fluorescence imaging of biological systems. Chem Rev. 2014; 114:84998541.

132. Zou X, Yao M, Ma L, Hossu M, Han X, Juzenas P, Chen W. $\mathrm{X}$-ray-induced nanoparticle-based photodynamic therapy of cancer. Nanomedicine (Lond). 2014; 9:2339-2351.

133. Hashiguchi S, Kusuzaki K, Murata H, Takeshita H, Hashiba M, Nishimura T, Ashihara T, Hirasawa Y. Acridine orange excited by low-dose radiation has a strong cytocidal effect on mouse osteosarcoma. Oncology. 2002; 62:85-93.

134. Mordon S, Cochrane C, Tylcz JB, Betrouni N, Mortier L, Koncar V. Light emitting fabric technologies for photodynamic therapy. Photodiagnosis Photodyn Ther. $2015 ; 12: 1-8$.

135. Garcez AS, Fregnani ER, Rodriguez HM, Nunez SC, Sabino CP, Suzuki H, Ribeiro MS. The use of optical fiber in endodontic photodynamic therapy. Is it really relevant? Lasers Med Sci. 2013; 28:79-85.

136. Fimple JL, Fontana CR, Foschi F, Ruggiero K, Song X, Pagonis TC, Tanner AC, Kent R, Doukas AG, Stashenko 
PP, Soukos NS. Photodynamic treatment of endodontic polymicrobial infection in vitro. J Endod. 2008; 34:728734.

137. Krieg AM. CpG motifs in bacterial DNA and their immune effects. Annu Rev Immunol. 2002; 20:709-760.

138. Xia Y, Gupta GK, Castano AP, Mroz P, Avci P, Hamblin MR. CpG oligodeoxynucleotide as immune adjuvant enhances photodynamic therapy response in murine metastatic breast cancer. J Biophotonics. 2014; 7:897-905.

139. Korbelik M, Cecic I. Enhancement of tumour response to photodynamic therapy by adjuvant mycobacterium cell-wall treatment. J Photochem Photobiol B. 1998; 44:151-158.

140. Korbelik M, Sun J, Posakony JJ. Interaction between photodynamic therapy and BCG immunotherapy responsible for the reduced recurrence of treated mouse tumors. Photochem Photobiol. 2001; 73:403-409.

141. Frampton JE. Mifamurtide: a review of its use in the treatment of osteosarcoma. Paediatr Drugs. 2010; 12:141153.

142. Creaven PJ, Cowens JW, Brenner DE, Dadey BM, Han T, Huben R, Karakousis C, Frost H, LeSher D, Hanagan J. Initial clinical trial of the macrophage activator muramyl tripeptide-phosphatidylethanolamine encapsulated in liposomes in patients with advanced cancer. J Biol Response Mod. 1990; 9:492-498.

143. Kleinerman ES, Jia SF, Griffin J, Seibel NL, Benjamin RS, Jaffe N. Phase II study of liposomal muramyl tripeptide in osteosarcoma: the cytokine cascade and monocyte activation following administration. J Clin Oncol. 1992; 10:1310-1316.

144. Kleinerman ES, Gano JB, Johnston DA, Benjamin RS, Jaffe N. Efficacy of liposomal muramyl tripeptide (CGP 19835A) in the treatment of relapsed osteosarcoma. Am J Clin Oncol.
$1995 ; 18: 93-99$.

145. Asano T, McWatters A, An T, Matsushima K, Kleinerman ES. Liposomal muramyl tripeptide upregulates interleukin-1 alpha, interleukin-1 beta, tumor necrosis factor-alpha, interleukin- 6 and interleukin- 8 gene expression in human monocytes. J Pharmacol Exp Ther. 1994; 268:1032-1039.

146. Korbelik M. Cancer vaccines generated by photodynamic therapy. Photochem Photobiol Sci. 2011; 10:664-669.

147. Gollnick SO, Vaughan L, Henderson BW. Generation of effective antitumor vaccines using photodynamic therapy. Cancer Res. 2002; 62:1604-1608.

148. Korbelik M, Merchant S. Photodynamic therapy-generated cancer vaccine elicits acute phase and hormonal response in treated mice. Cancer Immunol Immunother. 2012; 61:13871394.

149. Korbelik M, Stott B, Sun J. Photodynamic therapygenerated vaccines: relevance of tumour cell death expression. Br J Cancer. 2007; 97:1381-1387.

150. Korbelik M, Banath J, Saw KM, Zhang W, Ciplys E. Calreticulin as cancer treatment adjuvant: combination with photodynamic therapy and photodynamic therapy-generated vaccines. Front Oncol. 2015; 5:15.

151. Sotiriou E, Apalla Z, Vrani F, Lallas A, Chovarda E, Ioannides D. Photodynamic therapy vs. imiquimod 5\% cream as skin cancer preventive strategies in patients with field changes: a randomized intraindividual comparison study. J Eur Acad Dermatol Venereol. 2015; 29:325-329.

152. Ibbotson SH, Ferguson J. Ambulatory photodynamic therapy using low irradiance inorganic light-emitting diodes for the treatment of non-melanoma skin cancer: an open study. Photodermatol Photoimmunol Photomed. 2012; 28:235-239. 